\title{
A learned preference effect in the mouse using potassium deficiency as the induced need state
}

\author{
TARA K. SOUGHERS and FRANK ETSCORN \\ New Mexico Institute of Mining and Technology, Socorro, New Mexico 87801
}

\begin{abstract}
The reported study demonstrated the so-called learned preference effect using an unstudied need state, potassium deficiency, in Mus musculus. On a conditioning trial, potassium-deficient and nondeficient mice were offered various fluids sufficient or deficient in potassium. Subsequent preference tests pitting conditioning fluids against a sucrose solution indicated that all groups increased their preference for sucrose, except the deficient mice receiving oral replacement. These animals demonstrated a reliable increase in preference for the conditioning solution containing vinegar and potassium.
\end{abstract}

When consumption of a novel food is conditionally paired with negative postingestional consequences induced from such independent sources as x-irradiation (Garcia, Kimeldorf, \& Hunt, 1961) or drug injection (Garcia, Ervin, \& Koelling, 1966), the food will be avoided on subsequent encounters. These so-called conditioned food aversions have attracted a number of investigators interested in the complement to this effect, namely, an increased preference for a taste following its pairing with positive postingestional consequences. For example, rats made thiamine deficient tend to increase their preference for a distinctively flavored fluid when that fluid has been paired with thiamine replacement.

An early study of this learned preference effect (Garcia, Ervin, Yorke, \& Koelling, 1967) used rats maintained on a thiamine-deficient diet. After a clear onset of thiamine deficiency, the animals were allowed to drink saccharin solution followed $30 \mathrm{~min}$ later by an injection of thiamine. With four saccharin-thiamine pairings, the rats increased their intake of saccharin relative to a thiamine-deficient control group that drank water on thiamine injection days and saccharin solution on the days between injections.

Other studies using rats and thiamine deficiency have obtained similar results (Seward \& Greathouse, 1973; Zahorick, 1972; Zahorick \& Maier, 1969; Zahorick, Maier, \& Pies, 1974).

An extension to the study of these learned preferences has involved the manipulation of the induced need state. For example, Green and Garcia (1971) showed an enhanced preference for a distinctive fluid (either milk or grape juice) that had been offered to rats during the recuperation phase of the illness induced by a fastacting short-duration emetic (apomorphine). Parker,

Reprints of this article may be obtained from Frank Etscorn, Department of Psychology, New Mexico Tech, Socorro, New Mexico 87801. This research was supported by a Faculty Research Grant from New Mexico Tech awarded to the second author.
Failor, and Weidman (1973) likewise manipulated need state by allowing morphine-dependent rats to drink sucrose-octa-acetate (SOA) during acute morphine withdrawal with morphine injections immediately following, thus alleviating withdrawal distress. The results demonstrated that the morphine-dependent rats receiving SOA-morphine pairings increased their preference for SOA relative to nondependent rats that decreased their SOA consumption after identical SOAmorphine conditioning treatments.

Although the conditioning of these learned preferences appears to be a relatively robust phenomenon with certain need states, the rats' ability to learn preferences as a result of repletion from other need states is less clearly defined. For instance, Rodgers (1967) found that sodium replacement in sodium-deficient rats was an insufficient treatment for conditioning preferences to sodium-deficient diets; moreover, Rodgers suggested in the same report that, in the sodiumdeficient rat, sodium replacement may be aversive. Finally, Revusky and Garcia (1970) failed to demonstrate increased preferences for a saccharin solution following glucagon injections ( 75 micrograms) in hungry rats. The need state in this case was hunger, with the glucagon injections mimicking satiety. Parenthetically, humans injected with glucagon typically report sensations of satiety (Stunkard \& Wolff, 1958).

The present study was designed to extend the generality of these beneficial postingestional effects by using the mouse which has not been studied in the learned preference paradigm. Potassium deficiency was selected as the induced need state, since no reported studies have used this electrolyte to show increased preferences for tastes paired with its replacement. In addition, remission of the symptoms of potassium deficiency in humans generally occurs within $30 \mathrm{~min}$ to $2 \mathrm{~h}$ after oral potassium replacement therapy (Goodman \& Gilman, 1975). Facilitated conditioning would be expected over need states in which recovery is not as rapid. 


\section{METHOD}

\section{Subjects}

Subjects were 60 male Swiss-Webster mice obtained from Timco Breeding Laboratories in Houston, Texas. The mice were assigned at random to individual opaque plastic cages (19.5 $\times 29.2 \times 12.7 \mathrm{~cm}$ high) containing approximately $2 \mathrm{~cm}$ of shredded aspen bedding material. The galvanized wire-bar cage tops were modified to accommodate two drinking tubes that projected into the central portion of each cage. Drinking tubes were fashioned by affixing $5-\mathrm{cm}$ stainless steel sipper spouts to calibrated $(.2-\mathrm{ml}) 5$-cc disposable syringes. This arrangement allowed the spout tips of a pair of tubes when in a cage to be approximately $2 \mathrm{~cm}$ apart.

After initial cage assignments, all subjects were allowed to acclimate to the laboratory for 1 week before commencing daily body-weight determinations. Distilled water (from 200-ml bottles) and Wayne Lab Blox were available ad-lib for these 7 days.

The temperature of the laboratory was thermostatically maintained at approximately $24^{\circ} \mathrm{C}$, with overhead fluorescent strips cycled on at $0700 \mathrm{~h}$ and off at $1900 \mathrm{~h}$.

The mice remained in their home cages, except for nine weighings and bedding material changes.

\section{Apparatus}

Pellet diets were obtained from Teklad Test Diets of Madison, Wisconsin. Catalog numbers were 170550 for the potassiumdeficient diet (which contained a residual of $.002 \%$ potassium) and 170555 for the potassium-control diet. The cage-top food hoppers were filled with a minimum of test diet but were checked daily and replenished as needed from refrigerated stores.

\section{Procedure}

On Day 0 the standard Lab Blox Chow was removed from all cages and for half of the animals, replaced with the potassiumdeficient diet. The remaining mice were given the potassiumcontrol diet. The subjects were weighed at approximately the same time each day (to the nearest $.5 \mathrm{~g}$ ) on Days $0-9$. Following the determination of weights on Day 9 , all mice were deprived of their unflavored drinking water.

On Day 10 (conditioning day) the 30 mice eating the deficient diet were assigned at random to three equal groups. The animals having the control diet were likewise allocated to three groups. One group of deficient mice was then offered two drinking tubes filled from a solution consisting of $2.98 \mathrm{~g}$ of potassium chloride plus $2 \mathrm{ml}$ of vinegar (Piedmont distilled white) in $1,020 \mathrm{ml}$ of distilled water (def-vin- $\mathrm{KCl}$ group). A second group of deficient mice drank from a solution of $2 \mathrm{ml}$ of vinegar plus $2.5 \mathrm{~g}$ of sodium chloride added to 1 liter of distilled water (def-vin- $\mathrm{NaCl}$ group). The third deficient group received a solution of $2 \mathrm{ml}$ of vinegar in 1 liter of distilled water (def-vin-group). The three groups maintained on the potassiumcontrol diet received identical treatments. All mice had access for $30 \mathrm{~min}$ to their respective solutions. Pairs of drinking tubes were inserted into each cage and removed after the $30 \mathrm{~min}$ of drinking using 10 -sec intervals.

On Days 11 and 12 each mouse was given a simultaneous choice of its respective conditioning day solution and a novel $20 \%(\mathrm{w} / \mathrm{v})$ aqueous solution of sucrose. The cage placement of the two drinking tubes was determined at random for each mouse on Day 11, with the positions reversed for Day 12 .

\section{RESULTS}

Table 1 shows that by the second preference test, the deficient mice receiving oral replacement potassium on
Table 1

Mean Sucrose Preference Scores and Standard Errors of the Mean for Deficient and Control Animals

\begin{tabular}{lccccc}
\hline & \multicolumn{2}{c}{ Preference Test 1 } & & \multicolumn{2}{c}{ Preference Test 2 } \\
\cline { 2 - 3 } Group & Mean & SEM & & Mean & SEM \\
\hline & \multicolumn{4}{c}{ Control Diet } \\
Con-vin & 60 & 5.81 & 83 & 3.33 \\
Con-vin-NaCl & 66 & 6.32 & 81 & 5.83 \\
Con-vin-KCl & 57 & 6.92 & 78 & 5.62 \\
& & & Deficient & Diet & \\
Def-vin & 67 & 5.34 & 77 & 6.95 \\
Def-vin-NaCl & 68 & 5.07 & 75 & 6.92 \\
Def-vin-KCl & 63 & 7.44 & 47 & 9.82 \\
\hline
\end{tabular}

conditioning day were preferring the vinegar/potassium chloride solution over the more palatable sucrose solution when compared with the various control groups.

For statistical analyses, a sucrose preference score was determined for each mouse on each test day using the following formula: Amount of sweet water consumed divided by total of both fluids consumed times 100. A group by trials analysis of variance (ANOVA) with repeated measures on the second factor was performed on the preference scores of the three groups feeding on the control diet. The ANOVA indicated a significant trials effect $[F(1,54)=17.68, p<.001]$, but no reliable groups effect $[\mathrm{F}(2,54)<1]$ or Groups by Trials interaction $[F(2,54)<1]$. Hence each of the three groups fed the $\mathrm{KCl}$-control diet increased their relative preferences for sucrose solution from Day 1 to Day 2 of preference testing (Newman-Keuls, $p<.05$ in each case), with no differences in consumption existing between the groups.

An identical analysis of the three $\mathrm{KCl}$-deficient groups yielded a significant groups effect $[F(2,54)=$ $3.45, \mathrm{p}<.05]$, but no reliable effect of trials $[\mathrm{F}(1,54)$ $<1]$ or interaction $[F(2,54)=1.89, p>.05]$. A Newman-Keuls test indicated that no difference existed between the three $\mathrm{KCl}$-deficient groups on Test Day 1 ( $p>.05)$. On Test Day 2, however, the KCl-deficient animals drinking the vinegar- $\mathrm{KCl}$ solution on conditioning day demonstrated a significant (Newman-Keuls, $p<.05)$ reduction in sucrose preference compared with the other two $\mathrm{KCl}$-deficient groups. In summary, then, the $\mathrm{KCl}$-deficient mice drinking the vinegar- $\mathrm{KCl}$ solution on conditioning day increased their preference for this solution from Test Day 1 to Test Day 2 of preference testing compared with the deficient mice who did not receive oral replacement.

Supplementary analyses using separate one-way ANOVAs revealed that conditioning day liquid consumption did not differ among the three KCl-deficient groups $[F(2,27)=2.45, p>.05]$ or the three nondeficient groups $[F(2,27)=2.05, p>.05]$. However, a one-way ANOVA performed on the $\mathrm{KCl}$-deficient animals on Test Day 1 revealed a reliable difference 
between the three groups with respect to total fluid consumption $[F(2,27)=3.77, p<.05]$. A NewmanKeuls test showed that the def-vin- $\mathrm{KCl}$ group drank reliably less (an average of $2.8 \mathrm{ml}$ total fluid) than the def-vin-group $(3.3 \mathrm{ml}$ average, $\mathrm{p}<.05)$ or the defvin- $\mathrm{NaCl}$ group $(3.3 \mathrm{ml}$ average, $\mathrm{p}<.05)$. There were no differences observed in the three nondeficient control groups on Test Day 1 with respect to total fluid consumption $[F(2,27)<1]$. On Test Day 2 the deficient groups as well as the nondeficient groups showed no reliable differences in total fluid consumed $[F(2,27)<1$ in each case].

Finally, a one-way ANOVA was calculated for the weights of $\mathrm{KCl}$-deficient and nondeficient animals on Day 0 , and no differences were found $[F(1,58)=3.78$, $\mathrm{p}>.05$; deficient mice averaged $29 \mathrm{~g}$ and controls averaged $28 \mathrm{~g}$ ). By Day 9, however, there was a reliable difference, with the $\mathrm{KCl}$-deficient animals averaging $30 \mathrm{~g}$ and the nondeficient controls, $28 \mathrm{~g}[\mathrm{~F}(1,58)=7.42$, $\mathrm{p}<.01]$.

\section{DISCUSSION}

This experiment increases the generality of the learned preference effect by (1) demonstrating this effect in another species, Mus musculus, and (2) using a need state previously unstudied in this paradigm, potassium deficiency.

Note should be made of the potassium requirements for normal mouse development. Bell and Erfle (1958) demonstrated that in weanling mice ( $8-9 \mathrm{~g}$ initially), the potassium requirement was approximately .2\% of the total diet (the deficient diet in the present study contained a $.002 \%$ potassium residual). Bell and Erfle also noted that weanling mice fed a semipurified diet with no potassium supplement rapidly became emaciated and died within 5 or 6 days after being placed on the diet. Although our deficient and control groups evidenced no overt behavioral differences, the increased preference for the relatively unpalatable solution of vinegar and potassium chloride by the deficient animals suggests that a need state did exist for the potassium, albeit the degree of depletion was not such that weight loss or severe physiological problems developed. The def-vin as well as the def-vin- $\mathrm{NaCl}$ animals demonstrated increasing preferences, as might be expected, for the sucrose solution.

Technically, conditioning day represented a noncontingent presentation of novel fluid for all groups except the def-vin$\mathrm{KCl}$ group. Test Day 1 preferences for the less palatable conditioning day solutions may therefore be a result of learned safety (Kalat \& Rozin, 1973), since the sucrose solution was novel. We would further speculate that by Test Day 2 the beneficial effects of potassium repletion in the def-vin- $\mathrm{KCl}$ group had become sufficiently associated with the vinegar/ potassium chloride taste that a clear preference developed.

Finally, mention should also be made of a potential problem in this area of research. Barnes (1962) notes that rats as well as numerous other species practice autocoprophagy (an organism ingesting its own feces) even when fed a diet complete in all nutrients; moreover, with a vitamin-deficient diet, $100 \%$ of the feces may be consumed by the rat for short periods of time. Although we saw no coprophagic behavior in our animals, the opportunity was obviously available, especially since we used plastic, solid-bottom cages. Apparently, however, even wiremesh cages will not resolve this problem, as the vitamin-depleted rat will still eat approximately $35 \%-50 \%$ of its total fecal output by consuming the feces as they extrude from the anus. Indeed, we would predict that even more robust demonstrations of these learned preferences could be shown if the "recycling" of supposed depleted nutrients were eliminated. The extent to which coprophagy has occurred in this and other studies of this learned preference effect is unknown; however, as in the present study, the opportunity undoubtedly was available.

\section{REFERENCES}

Barnes, R. H. Nutritional implications of coprophagy. Nutritional Reviews, 1962, 20, 289-291.

Bell, J. M., \& Erfle, J. D. The requirement for potassium in the diet of the growing mouse. Canadian Journal of Animal Science, 1958, 38, 145-147.

Garcia, J., Ervin, F. R., \& Koelling, R. A. Learning with prolonged delay of reinforcement. Psychonomic Science, 1966, 5, 121-122.

Garcia, J., Ervin, F. R., Yorke, C. H., \& Koelling, R. A. Conditioning with delayed vitamin injections. Science, 1967, 155, 716-718.

Garcia, J., Kimeldorf, D. J., \& Hunt, E. L. The use of ionizing radiation as a motivating stimulus. Psychological Review, 1961, 68, 383-395.

Goodman, L. S., \& Gilman, A. (Eds.). The pharmacological basis of therapeutics (5th ed.). New York: Macmillan, 1975.

Green, K. F., \& Garcia, J. Recuperation from illness: Flavor enhancement for rats. Science, 1971, 173, 749-751.

Kalat, J. W., \& Rozin, P. "Learned safety" as a mechanism in long-delay taste aversion learning in rats. Journal of Comparative and Physiological Psychology, 1973, 83, 198-207.

Parker, L. F., Failor, A., \& Weidman, K. Conditioned preferences in the rat with an unnatural need state: Morphine withdrawal. Journal of Comparative and Physiological Psychology, 1973, 82, 294-300.

REVUSKY, S., \& G ARCIA, J. Learned associations over long delays. In G. H. Bower \& J. T. Spence (Eds.), The psychology of learning and motivation: Advances in research and theory (Vol. 4). New York: Academic Press, 1970.

RODGERS, W. L. Specificity of specific hungers. Journal of Comparative and Physiological Psychology, 1967, 64, 49-58.

Seward, J. P., \& Greathouse, S. R. Appetitive and aversive conditioning in thiamine deficient rats. Journal of Comparative and Physiological Psychology, 1973, 83, 157-167.

Stunkard, A. J., \& WolfF, H. G. Pathogenesis in human obesity: Function and disorder of a mechanism of satiety. Psychosomatic Medicine, 1958, 20, 19-29.

ZAHORIK, D. M. Conditioned physiological changes associated with learned aversions to tastes paired with thiamine deficiency in the rat. Journal of Comparative and Physiological Psychology, $1972,79,189-200$.

Zahorik, D. M., \& MaIER, S. F. Appetitive conditioning with recovery from thiamine deficiency as the unconditioned stimulus. Psychonomic Science, 1969, 17, 309-310.

Zahorik, D. M., Maier, S. F., \& Pies, R. W. Preferences for tastes paired with recovery from thiamine deficiency. Journal of Comparative and Physiological Psychology, 1974, 87, 1083-1091.

(Received for publication June 2, 1980.) 